\title{
Motivational effects in probability learning
}

Forty rats were nu in a 70:30 probability leaming $T$ maze situation. A 2 by 2 factorial design combined high and low incentive. The hypothesis was that under relatively low motivation, the fixated or maximizing behavior typically found in rats should give way to distribution of response to both goals. This hypothesis was supported. Within the small number (110) of trials run, probability matching was not observed, though the possibility of its later appearance was not ruled out by the behavior of the low-motivated Ss. Unexplainable emotional behavior was noted in some Ss.

In spite of a lasting interest in animal probability learning, probability matching (PM) behavior is extremely difficult to observe in mammals. Early reports of it (Lauer \& Estes, 1954; Hickson, 1961) have involved various artifacts (Bitterman, 1964). In essentially all rat studies, Ss have fixated or maximized response to one or the other of the two goals; only in decorticated rats has random PM been reported (Gonzales, Roberts, \& Bitterman, 1964). However, there is systematic evidence (Bitterman, 1965) that submammals show typical random PM, and it has been inferred that different learning mechanisms may account for this phyletic difference.

This inference has two weaknesses: (a) that the rat does show PM when decorticated, and (b) that submammalian vertebrates (birds and turtles) show PM under some conditions, maximizing under others (Bullock \& Bitterman, 1962; Kirk \& Bitterman, 1965). Such evidence suggests a ubiquitous common mechanism (very plausibly, stimulus sampling; see Estes, 1959) which leads to $P M$, but which in the higher animals is subordinate to other "maximizing" mechanisms lacking or less important in the lower phyla. This alternative inference requires identification of this putative maximizing mechanism.

The present study was of drive (D) and incentive (K) effects in probability learning. Motivation has been little studied, and is usually at a high level, in animal probability learning situations. Studies reporting nonfixated mammalian PM have apparently involved relatively low $D$ and $K$ (Uhl, 1963; Wilson, Oscar, \& Bitterman, 1964). Also, by Hull-Spence theory, to the extent that the difference between two competing response strengths is magnified by $D$ and $K$, the stronger response should occur increasingly at the expense of the weaker, the limiting case being maximizing under very high $D$ and $K$. Accordingly, under low $\mathrm{D}$ and $\mathrm{K}$, nonfixated (possibly $\mathrm{PM}$ ) behavior might be expected.

Method

The Ss were 40 adult female albino rats, run 110 trials (three per day) in a spatial 70:30 $\mathrm{T}$-maze problem with free correction. A factorial design combined two levels of D (23 and $2 \mathrm{hr}$. food deprivation) with two levels of $\mathrm{K}$ (rewards of $250 \mathrm{mg}$. and $37 \mathrm{mg}$.), with $10 \mathrm{Ss}$ per group. Dependent variables were: (a) number of nonfixated responses (approaches to the least-approached goal) per block of 10 trials, and (b) running speed in the 30 in. long stem alley. The least-approached goal was defined by individual preference over the last 40 trials.

Resulis

Figure 1 shows the response proportions within blocks of 10 trials for all Ss in the four groups. Response toward the 70 percent reinforced goal was designated $A_{1}$; toward the 30 percent side, $A_{2}$. Visual inspection indicates considerable differences in maximizing tendency to either $A_{1}$ or $A_{2}$ as a function of $D$ and $K$, high $K$ and to a lesser extent high $D$ being associated with maximizing. With only a few exceptions (mostly in the low-K groups), preference for $A_{1}$ or $A_{2}$ was established within the first 50 trials. An overall Kruskal-Wallis analysis of variance by ranks was performed on the total number of nonfixated responses per $S$ over the last 40 trials; the differences in fixatedness were significant, with $H(3)=$ 132.996, $p<.001$. To test the main effects of $D$ and $K$, the Mann-Whitney $U$ test was used. The effect of D was not significant. With correction for tied scores, the $\mathrm{K}$ effect was significant at the 0.01 level. Clearly, in this situation there was a strong interaction between $\mathrm{D}$ and $\mathrm{K}$. Although occurrence of nonfixated responses was apparently random, PM did not occur.

Running speeds are shown in Fig. 2. Although higher motivation was associated with faster running, the asymptotic speeds reached under all levels of motivation would suggest that differences in fixatedness

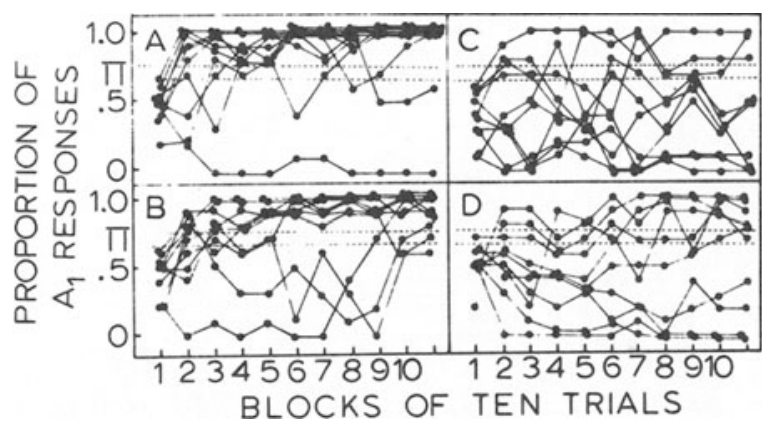

Fig. 1. Distributions of $A_{1}$ (70\% rewarded) response proportions within 10-trial blocks: $A-23$ hours $D, 250 \mathrm{mg} K$; $B-2$ hours $D$, $250 \mathrm{mg}$ K; $C$ - 23 hours D, $37 \mathrm{mg}$ K; D -2 hours D, $37 \mathrm{mg} \mathrm{K}$. 


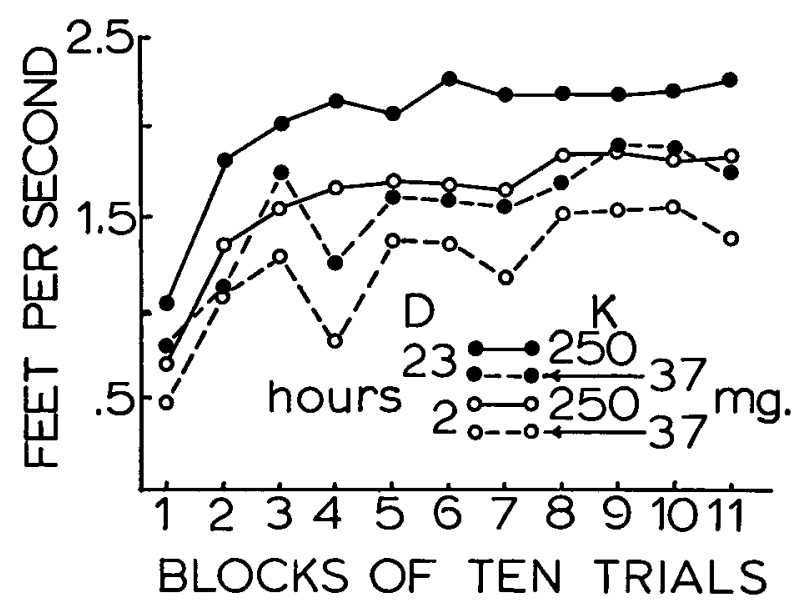

Fig. 2. Starting-running speeds in stem alley, as a function of $\mathbf{D}$ and $\mathbf{K}$.

cannot be attributed to gross differences in learning rate.

From Trial 30 onward, every $S$ in Group C (high D, low $K)$ exhibited very strong emotional responses (defecation, urination, climbing, and biting) at the choice point and in the reinforced goal box. These Ss, and those in Group D (low D, low K) also resisted placement into the start box. Starting and running times were visibly impaired by these behaviors, which were very similar to those seen in extinction following continuous reward.

Diseussion

In this preliminary study, far too few trials were run to allow search for reliable random PM. The data do show that intact adult rats in probability learning paradigms need not necessarily fixate upon one goal alternative. Whether PM would occur under very low $\mathrm{D}$ and $\mathrm{K}$ over extended training is still an open question. The present data do not exclude the possibility. A second question is whether the emotional correlates of small incentive in probability learning are reliable and significant.

\section{References}

Bitterman, M. E. Species differences in learning. A. P. A. Symposium on interspecies comparisons of behavior, 1963 .

Bitterman, M. E. Phyletic differences in learning. Amer. Psychologist, 1965, 20, 396-410.

Bullock, D. H., \& Bitteman, M. E. Probability-matching in the pigeon. Amer. J. Psychol., 1962, 75, 634-639.

Estes, W. K. The statistical approach to learning theory. In Koch, Psychology: a study of a science, Vol. 2. New York: McGrawHill, 1959.

Gonzales, R. C., Roberts, W. A., \& Bitterman, M. E. Learning in adult rats with extensive cortical lesions made in infancy. Amer. J. Psychol., 1964, 77, 547-562.

Hickson, R. H. Response probability in a two-choice learning situation with varying probability of reinforcement. J. exp. Psychol., 1961, 62, 138-144.

Kirk, Kathleen L., \& Bitterman, M. E. Probability-learning by the turtle. Science, 1965, 148 (Whole No. 3676), 1484-1485.

Lauer, D. W., \& Estes, W. K. Observed and predicted terminal distributions of response probability under two conditions of random reinforcement. Amer. Psychologist, 1954, 9, 413.

Uhl, C. N. Two-choice probability learning in the rat as a function of incentive, probability of reinforcement, and training procedure. J. exp. Psychol., 1963, 66, 443-449.

Wilson, W. A., Jr., Oscar, Marlene, \& Bitteman, M. E. Probabilitylearning in the monkey. Quart. J. exp. Psychol., 1964, 16, 163165 . 